\title{
Hot water irrigation as treatment for intractable posterior epistaxis in an out-patient setting
}

\author{
E NOVOA, C SCHLEGEL-WAGNER
}

\author{
Department of Otorhinolaryngology, Head and Neck Surgery, Kantonsspital Luzern, Lucerne, Switzerland
}

\begin{abstract}
The management of intractable posterior epistaxis is challenging for any physician. Nasal packing, often combined with use of an endonasal balloon system, is painful for the patient, and torturous to maintain for two to three days. If conservative treatment fails, the most commonly used treatment options are currently invasive procedures such as endoscopic coagulation of bleeding arteries, external ligation and, rarely, embolisation. This paper describes a simple, non-invasive technique of treating posterior epistaxis with hot water irrigation. Technical information is presented, and the benefits of the method are discussed.
\end{abstract}

Key words: Epistaxis; Irrigation; Water; Balloon Tamponade

\section{Introduction}

Hot water irrigation was first described by N L Guice in 1878 (N L Guice treated the first patient in 1878, but published it in 1884) as an effective method of treating severe, life-threatening epistaxis. ${ }^{1}$ However, the technique was already in use by nineteenth century obstetricians as a method of treating postpartum bleeding. ${ }^{2}$

In the second half of the twentieth century, newer nasal packing products and the development of endoscopic sinus surgery almost completely replaced the irrigation technique as treatment for posterior epistaxis.

However, Stangerup et al. have recently demonstrated that hot water irrigation, using temperatures of up to $50^{\circ} \mathrm{C}$, produces vasodilation and oedema of the nasal mucosa without the risk of necrosis. ${ }^{3}$ This mucosal oedema leads to local compression of the bleeding vessels, while at the same time triggering and probably accelerating the clotting cascade. In Stangerup's series, hot water irrigation had a higher success rate (55 per cent) in treating posterior epistaxis, compared with nasal packing (44 per cent). ${ }^{4}$ Using a modified irrigation technique, our group was able to stop bleeding permanently in up to 82 per cent of cases of intractable posterior epistaxis, including patients receiving antiplatelet agents or anticoagulants. ${ }^{5}$ We encountered no complications, such as crusting or synechiae formation, during a follow-up period of four to 24 months. Furthermore, successful hot water irrigation was associated with less nasal trauma, significantly less pain, fewer surgical procedures and avoidance of a hospital stay. ${ }^{4,5}$ Hot water irrigation is currently used in our clinic as the first line of treatment for posterior epistaxis.

This report presents a complete description of the method, as well as technical details and practical suggestions.

\section{Method}

Topical anaesthesia of the relevant nasal cavity is applied using cotton nasal packing impregnated with 4 per cent tetracaine. An Epicat balloon catheter (Abigo Medical AB, Askim, Sweden) is inserted into the affected nasal cavity (Figure 1a). This modified bladder catheter has an irrigation opening located proximal to the balloon. The balloon is inflated within the epipharynx using saline, and then gently pulled back until the choana is blocked off, in order to avoid aspiration (Figure 1b). The proximal irrigation opening enables free flow of irrigation water in the region of the sphenopalatine foramen.

The affected nasal cavity is then continuously irrigated during 3 minutes with $500 \mathrm{ml}$ water heated to $50^{\circ} \mathrm{C}$ (we treat with $500 \mathrm{ml}$ of hot water using a caloric stimulator. This takes about 3 minutes). Tap water is administered via a water caloric stimulator (conventionally used for vestibular testing) (Figure 2). The metallic tip of the caloric irrigator is inserted into the distal end of the balloon catheter. The patient is then seated upright with their face pointed downward over a basin, to allow outflow of water from the affected nasal cavity into the basin (see video clip; Appendix 1). The caloric stimulator has been technically modified to produce the desired water temperature, providing a continuous flow of hot water without fluctuations of temperature. ${ }^{5}$

Most patients stop bleeding during hot water irrigation. Generally, we would expect bleeding to stop after 10 minutes of continuous treatment. The catheter can then be removed, or left in place for several minutes in case a second irrigation is needed.

Once bleeding is successfully stopped, patients can be discharged home after a two-hour observation period.

Figure 3 shows an algorithm guiding hot water irrigation treatment for posterior epistaxis.

\section{Practical advice}

We would offer the following practical suggestions on administering hot water irrigation as treatment for intractable posterior epistaxis. 
(a)

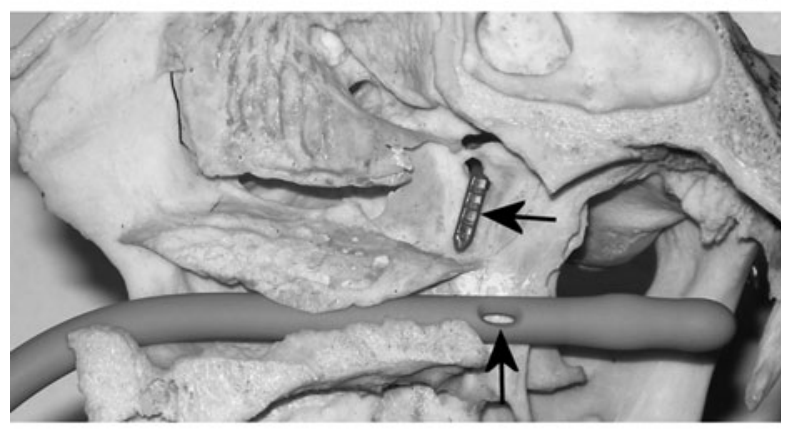

(b)

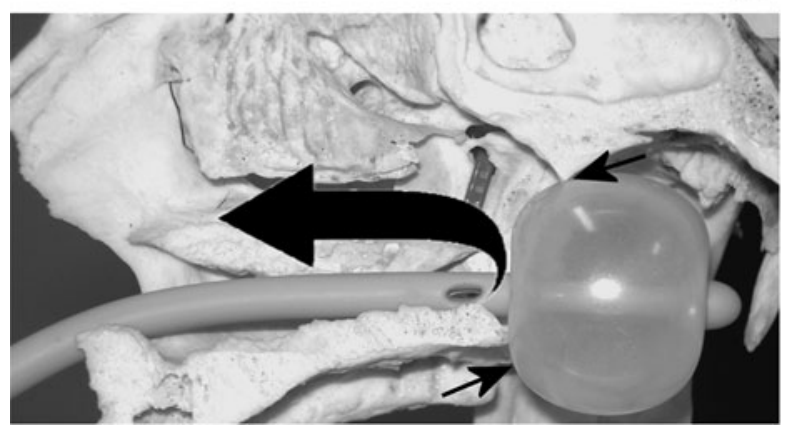

FIG. 1

(a) Correct placement of the modified balloon catheter along the inferior meatus, with the orifice of the catheter (arrow) placed underneath the sphenopalatine foramen (second arrow). (b) The large arrow indicates the direction of water flow through the nose during continuous irrigation, while the small arrows show the correct placement of the inflated balloon, anchored within the choana

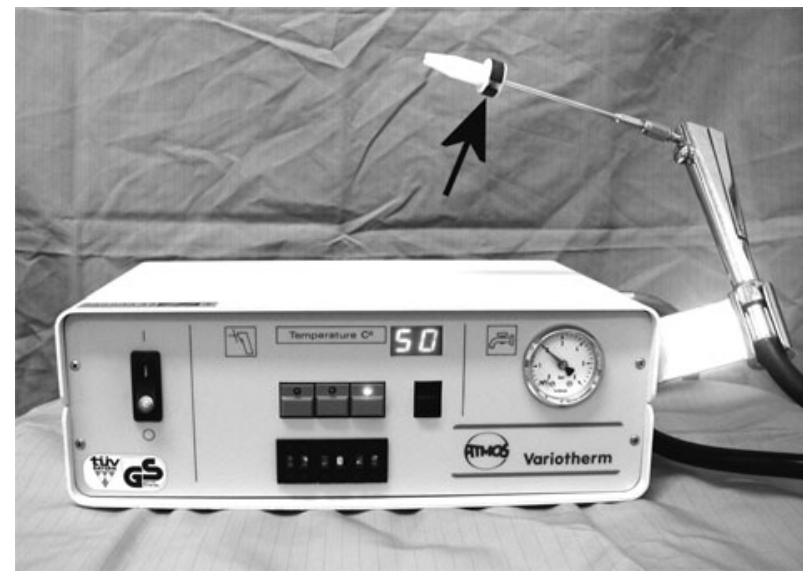

FIG. 2

A conventional caloric irrigator which has been technically modified to allow a water temperature of $50^{\circ} \mathrm{C}$. The arrow indicates the protective valve that must be occluded with a finger during irrigation in order to prevent backflow of water.

Firstly, it is important to normalise vital signs prior to hot water irrigation. Patients commonly present with elevated blood pressure, which must be addressed first. Anticoagulant or antiplatelet therapy should be suspended whenever possible. Consumption of acetylsalicylic drugs is common, often routinely prescribed as stroke prophylaxis; such drugs have been shown to be one of the major risk factors for epistaxis

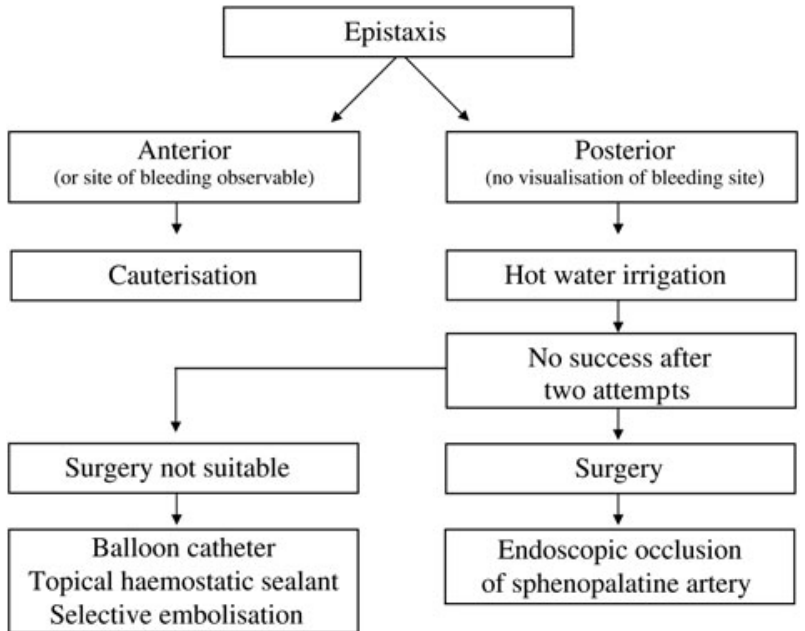

FIG. 3

Treatment algorithm.

occurrence and severity. ${ }^{6}$ After discharge, the indication for these drugs should be discussed with the patient's referring physician, general practitioner or cardiologist.

In cases with a visible source of bleeding, cauterisation by any means should be attempted prior to hot water irrigation.

In cases of haemorrhagic shock, bleeding must be stopped immediately using a balloon catheter or urgent surgery.

Clinicians should avoid the use of nasal vasoconstrictors before commencing hot water irrigation, in order not to interfere with the formation of nasal mucosa oedema.

Severe septal deviations do not constitute any inconvenience as regards hot water irrigation, provided the catheter can be correctly placed.

The balloon catheter must be well placed and not bent, and must be anchored within the choana. If water flows out through the mouth, the balloon is certainly not in place. The protective valve at the tip of the caloric irrigator must be occluded with a finger in order avoid backflow of water.

After two failed hot water irrigation attempts, conventional nasal packing and surgical exploration are recommended.

Hot water irrigation is not effective in cases of post-operative bleeding after endonasal surgery of the turbinates or paranasal sinuses, as there is insufficient intact mucosa to sustain local oedema.

Finally, if a caloric irrigator is not available, hot water irrigation can still be performed using a large $100 \mathrm{ml}$ syringe and a thermo-bucket filled with $50^{\circ} \mathrm{C}$ tap water. It is important to note that at least $500 \mathrm{ml}$ of water should be irrigated through the nose in each 3 minute period. However, this alternative method is not encouraged, as the temperature and amount of instilled water are difficult to control.

\section{Conclusion}

Hot water irrigation constitutes a safe, efficient and costeffective treatment method for posterior epistaxis. This method has the additional benefits of less patient discomfort, less morbidity, less need for surgical intervention and fewer days of hospitalisation.

Hot water irrigation should be considered as the first line of treatment for posterior epistaxis, and medical trainees should be repeatedly instructed in its use in out-patient and emergency settings. 


\section{References}

1 Guice NL. Hot water in epistaxis. Miss Valley Med Month 1884;4: 3-4

2 Hansen TB. Hot water irrigation to obtain haemostasis [in Danish]. Bull Midwifes (Copenh) 1890;3:8-10

3 Stangerup SE, Dommerby H, Lau T. Hot-water irrigation as a treatment of posterior epistaxis. Rhinology 1996;34:18-20

4 Stangerup SE, Dommerby H, Siim C, Kemp L, Stage J. New modification of hot-water irrigation in the treatment of posterior epistaxis. Arch Otolaryngol Head Neck Surg 1999·125:686-90

5 Schlegel-Wagner C, Siekmann U, Linder T. Non-invasive treatment of intractable posterior epistaxis with hot-water irrigation. Rhinology 2006;44:90-3

6 Soyka MB, Rufibach K, Huber A, Holzmann D. Is severe epistaxis associated with acetylsalicylic acid intake? Laryngoscope 2010;120:200-7

\section{Appendix 1.Supplementary video material}

A video clip demonstrating the application of hot water irrigation in a patient with epistaxis is available on
The Journal of Laryngology \& Otology website, at http:// journals.cambridge.org/sup_S002221511100243Xsup001.

\author{
Address for correspondence: \\ Dr Eva Novoa, \\ Department of Otorhinolaryngology, \\ Head and Neck Surgery, \\ Kantonsspital Luzern, \\ 6000 Lucerne 16, Switzerland
}

Fax: +410412054995

E-mail: eva.novoa@ksl.ch

Dr E Novoa takes responsibility for the integrity of the content of the paper

Competing interests: None declared 